\title{
ARMAS Y LETRAS
}

Juan Antonio Rosado*

\section{Toda gran literatura, como todo}

gran hombre, nos comunica la relación dialéctica entre lo metafísico y lo social. Así como no hay hombres solos, tampoco hay obras artísticas solas. Toda creación del espíritu, toda producción del intelecto se inserta en una tradición, en una cultura, de la que sólo puede escapar para morir en silencio. Mientras viva -gracias al lector que le da vida, pero también al traductor, al crítico, al pueblo mismo que se ha apropiado de ciertos referentes para llevarlos a otros planos- la creación seguirá dialogando con el entorno y con otras obras. El mismo ensayista suele propiciar estos últimos diálogos, al asociar, al establecer vínculos -a veces válidos, a veces productos de la imaginación crítica- entre obras diversas, de las que en ocasiones el autor no tuvo idea de su existencia. Y es que la cultura está hecha a base de sistemas de vasos comunicantes donde la interrelación de las obsesiones, de los temas, de las preocupaciones recurrentes e incluso de determinadas formas externas de la creación, no sólo pueden salir a flote sin que el creador se percate de ello, sino que incluso pueden provenir de espacios y tiempos insospechados de una manera más o menos directa. Tal es el caso, por ejemplo, del Calila e Digna, cuyos cuentos son adaptaciones del libro árabe Calila wa Dimna, que a su vez es una traducción de algunas partes del Panchatantra sánscrito de la India antigua. La idea 'abismal' de los cuentos dentro de cuentos se halla en el libro sánscrito y es retomada por sus descendientes ignorando a menudo su origen. Así es: no hay obras solas porque no hay nada que provenga de la nada, por más

* Facultad de Filosofía y Letras, UNAM; Centro de Lenguas, ITAM. 
originalidad que pretenda poseer. Miguel de Cervantes (1547-1616), quien toma un gran número de elementos reales y librescos, no puede ser la excepción.

En este sentido, si es cierto que el autor de El ingenioso hidalgo don Quijote de la Mancha (1605, 1615) deplora explícitamente una de sus fuentes más importantes -la novela de caballería-, también lo es que el Quijote, como obra literaria, va mucho más allá de esta condena. En principio, lo más probable es que Cervantes haya utilizado la argucia o el engaño de la condena a las novelas de caballería y de la figura del caballero idealista para distraer la atención de otros temas, mucho más profundos y por ello mucho más 'peligrosos'. Como dice Victor Hugo en su libro sobre William Shakespeare: "La burla del ideal sería gran defecto en Cervantes, pero este defecto no es más que aparente; observad con atención y veréis que en su sonrisa hay una lágrima. En realidad, Cervantes simpatiza con Don Quijote, como Molière con Alcestes. Es preciso saber leer en esos libros, y en particular en los del siglo XVI: a causa de las amenazas que pesaban sobre la libertad de pensar, hay en la mayor parte de ellos un secreto que es necesario abrir con una llave que se pierde con frecuencia."

No es casual que en el título del Quijote encontremos la palabra 'ingenioso'. En su Tesoro de la lengua castellana o española (1611), Sebastián de Cobarruvias define el ingenio como una fuerza natural de entendimiento, que investiga lo que por razón y discurso puede alcanzarse "en todo género de ciencias, disciplinas, artes liberales y mecánicas, sutilezas, invenciones y engaños". Con el Quijote, el ingenioso Cervantes quiere también distraer la atención de los lectores tontos, que sólo buscan diversión en su obra, donde se afirma claramente que todo libro debe divertir pero también enseñar. ¿Qué enseña esta producción fundamental del ingenio español? Muchas cosas, pero antes de pasar a esta obra y, en particular, a uno de los más importantes discursos - por sus repercusiones en el campo social y político- de don Quijote (el famoso discurso sobre las armas y las letras), no debemos escatimar una breve ojeada a las novelas de caballería, donde las 
armas -al igual que en la antigua poesía épica- son representadas por las letras.

Cuando Christopher Keller propuso su famosa, aunque simplista y esquemática división de la historia occidental en Edad antigua, Edad media y Edad moderna, contribuyó a aumentar el prejuicio que atraparía y encasillaría en estereotipos hoy obsoletos a más de diez siglos de historia conocidos como Edad media. Ciertamente, un gran número de acontecimientos ocurrió durante diez siglos. Pero si Keller (o Cellorius) y los intelectuales del humanismo provocaron la visión de la Edad media como una etapa oscurantista, los románticos de finales del siglo XVIII provocaron otro prejuicio, tan fundado en la ignorancia como el primero. A pesar de esto, la visión 'romántica' de la Edad media como una época de caballeros sometidos a la dama y privados -en parte- de la belicosidad que siempre distinguió al miles o guerrero, no se originó de la nada.

Importantes cambios se manifestaron a partir del siglo X y XI, entre los que cabe destacar la imposición de una cierta idea de la institución matrimonial para obligar a los laicos a seguir las formas de vida que, según los sacerdotes, agradaban a Dios. Había que prepararse para el fin del mundo y la Iglesia pretendía ampliar su poder de organización a todos los ámbitos. Se debe tomar en cuenta el surgimiento del culto oficial de la virgen María debido a la amenaza de la secta de los cátaros, que empezaba a poner en jaque el poder político de la Iglesia en el siglo XII.

En ese siglo se impuso el celibato a los sacerdotes, reservado hasta entonces sólo para los monjes. En otros aspectos, con el advenimiento del feudalismo, que empieza a adquirir fisonomía precisa durante el siglo IX, el hombre al servicio de las armas ya era calificado en los textos como miles (guerrero), pero, bajo este vocablo, se advierte, latinizado, un término del habla: caballarius, caballero, que estaba sometido, 'entregado' al dueño del castillo y, por lo tanto, era parte de su 'familia'. Se trataba de un guerrero 'privado' cuyos rasgos de belicosidad dejarán de ser lo único que lo caracteriza. 
Además del sometimiento al 'señor' o al rey, el concepto de 'amor cortés', impulsado por los trovadores, será materia decisiva en la formación de las primeras novelas caballerescas hispánicas: la historia épica se transforma en historia 'cortés' sin perder del todo los elementos y rasgos épicos. No obstante, es una constante en muchas de estas obras la ruptura del caballero con el rey debida a los 'malos consejos' o 'calumnias' de los envidiosos, como ocurre en el Cantar de Mio Cid y en la primera novela caballeresca hispánica, El caballero Cifar, en las que el buen caballero se enfrenta a un 'mal señor'. Con el tiempo, la monarquía se fortalecería nuevamente, lo que hizo que las novelas de caballería del siglo XIV no osaran ya referirse al rey como un 'mal Señor'. Lo importante es que, en términos generales, desde El caballero Cifar encontramos tres temas decisivos: la cortesía como elemento amoroso, la hagiografía como elemento sacralizador, y la heroicidad del ingenioso caballero en pro del bien social o de un grupo determinado: el nivel erótico, el moralizante y la función político-social se hermanan a través de la representación épica.

Para C. S. Lewis, el noble guerrero se transforma en caballero cuando hace su aparición el mundo de la corte y la llamada 'cortesía'.

El guerrero tiene entonces que adquirir las cualidades de la cortesía y el refinamiento, además de las que ya lo caracterizaban como combatiente. Johan Huizinga hace notar que "está embebida del ideal caballeresco la ideología de aquel grupo que vive en la esfera de la corte y de la nobleza". Pero también, gracias a los modos y paradigmas de la cortesía, aparece -desde la literatura sobre el rey Arturo- otra cualidad del gran guerrero y vasallo leal que es el caballero: la belleza física, notable en Amadís de Gaula y también en los siete hijos de Isomberta, en El caballero del cisne.

Además de la 'cortesía', ausente en los cantares de gesta como el $\mathrm{Cid}$, son notorias otras influencias literarias en las novelas caballerescas hispánicas, como la que ejerció, en menor medida, el 'ciclo carolingio' (sobre el rey Carlo Magno). Más importantes en este sentido fueron las novelas bizantinas - de aventuras, pérdidas, encuentros y desencuentros, tensión narrativa que resalta en el Libro de Apolonio (s. XIII), 
manifestación del llamado mester de clerecía o de clérigos- y, sobre todo, el llamado ‘ciclo bretón' o materia 'artúrica'.

Si la literatura española, desde el Cantar de Mio Cid, se ha caracterizado por su realismo, será precisamente gracias a los textos de tema artúrico - a decir de varios críticos- que las novelas caballerescas hispánicas como El caballero del cisne adquieran elementos fantásticos y sobrenaturales. Es la injerencia de estos ingredientes lo que más provocará la famosa condena de Cervantes en el Quijote, pues la novela picaresca reivindicará un realismo contundente, que volverá a aparecer en la magna obra del autor complutense.

Es necesario reflexionar sobre la 'condena' cervantina, que ha producido también un prejuicio contra las lecturas favoritas del ingenioso hidalgo. En primer lugar, el erasmista Miguel de Cervantes no condena la novela caballeresca como género, ya que el sacerdote -en la quema de la biblioteca de Alonso Quijano- rescata varias novelas caballerescas y pastoriles, lo que implica que el autor sólo se hallaba en contra de lo que él consideraba como malas novelas. Cuando el cura decide quemar los cuatro libros del Amadís de Gaula, el barbero se opone: "he oído decir que es el mejor de todos los libros que de este género se han compuesto; y así, como a único en su arte, se debe perdonar" (Don Quijote, I, VI), a lo cual accede el cura. En cambio, la continuación del Amadís, escrita por su corrector (Garci Rodríguez de Montalvo) y llamada Sergas de Esplandián, es lanzada al fuego. El mismo destino se reserva para otros textos menores, como el Amadís de Grecia, Don Olivante de Laura y el primero de la serie de los palmerines, llamado Palmerín de Oliva. En cambio, rescata el Palmerín de Inglaterra y, sobre todo, la Historia del famoso caballero Tirante el Blanco, "un tesoro de contento y una mina de pasatiempos" (Don Quijote, I, VI). El autor complutense, sin embargo, no menciona ni $\mathrm{El}$ caballero del cisne ni El caballero Cifar, los dos libros caballerescos hispánicos más antiguos de que se tenga noticia.

En la 'Introducción' a su Antología de libros de caballería hispánicos, José Amezcua afirma que es indispensable separar, 'emancipar' todos estos textos de la obra de Cervantes y estudiarlos de modo inde- 
pendiente. Sólo así dejaremos de considerar a estas obras como textos 'anacrónicos': temas como el amor secreto y la sensualidad que allí se filtra, el doble matrimonio de Cifar -aunque resuelto por la vía moral de la castidad del caballero y la muerte de la segunda esposa- vislumbran claramente una flexibilidad de las normas que prefigura algunos aspectos del Renacimiento. En estas obras, el caballero cobra dimensiones carnales y no tan sólo símbólicas o ideales. No por nada el medievalista Jacques LeGoff considera que el Renacimiento es una parte de la Edad media. En efecto, el término 'Renacimiento' pertenece, en sus orígenes, a la crítica de arte y fue acuñado por los historiadores del arte, quienes sólo se refirieron a esta manifestación cultural sin tomar en cuenta los demás aspectos de la vida (política, economía, ciencias...). En la literatura -manifestación cultural que desde el Cid y desde antes del Cid jamás se apartó, en términos generales, de su función política-hubo, sin dudas, un renacimiento anterior al de la pintura y la escultura.

Desvinculados de los prejuicios contra las novelas caballerescas, podemos apreciar en ellas una estructura mítica del héroe como portador de los valores explícita o implícitamente aceptados como positivos por el autor y por el contexto general de la época y la obra: cualidades espirituales inigualables conjugadas con la fortaleza física y el ingenio. Además, es notoria una cierta continuidad de temas míticos, como las condiciones del mismo nacimiento del héroe; por ejemplo, a Amadís se le coloca en un cesto y se le deja en un río, y a los siete infantes de Isomberta los cuida una cierva.

Afirma José Amezcua que "los libros de caballerías fueron el primer experimento europeo para probar la elasticidad del género novelesco". En este sentido, la lectura y el estudio desprejuiciado de estas obras son también indispensables para comprender el desarrollo, la evolución, la historia del arte de la novela en la cultura occidental.

No es ninguna casualidad que Cervantes haya dirigido su atención hacia los nexos entre la belicosidad (la acción de las armas) y las letras (el encierro, la pasividad física). Don Quijote -y no Alonso Quijanose caracteriza, ante todo, por su vitalismo desenfrenado, por su apego 
a los fenómenos de carácter social, como cuando protege al pastorcillo Andrés o libera-después de interrogarlos sobre el carácter de sus delitos- a los galeotes. El protagonista del Quijote es un hombre que se niega a morir. Este anhelo de ir más allá de los límites individuales que nuestro cuerpo, nuestro espacio y nuestra vida en general nos marcan, es precisamente la antítesis de la pasividad, del conformismo y del encierro. Como buen caballero, el ingenioso hidalgo don Quijote posee la energía suficiente para negarse a morir y proclamar su credo en sucesivos discursos de gran profundidad y de envergadura universal. Don Quijote está lleno de esta carga vital, caballeresca, que lo hace alejarse constantemente de la inmovilidad que representaría, por ejemplo, la muerte, a la que no teme por su mismo ímpetu. Cuando Sancho Panza habla del sueño y asegura que éste iguala al pastor con el rey y al simple con el discreto, coloca a todos los humanos en el mismo plano, sin distinción, y de ahí el gran valor social que incluye tal aseveración, pero a la vez reconoce que "sola una cosa tiene mala el sueño [...] y es que se parece á la muerte, pues de un dormido á un muerto hay muy poca diferencia" (II, 68). Sancho compara el sueño con la muerte, con la pasividad absoluta, con la inercia de la que don Quijote huye. La muerte, asunto que se trata en distintos pasajes de la magna obra, ha sido una de las grandes preocupaciones y motivos de reflexión en todas las culturas del mundo, ya que es precisamente el terror a la muerte, como asegura Oswald Spengler, el origen de las lucubraciones metafísicas, que surgen primeramente porque el ser humano es consciente de ser mortal. Las preguntas: ¿quiénes somos?, ¿por qué estamos aquí?, ¿hacia dónde vamos después de morir? son preguntas universales; carecen de tiempo y de espacio, y constituyen uno de los múltiples temas del gran diálogo mundial, de ese gran sistema de vasos comunicantes que une a obras como el Poema de Gilgamesh, El libro de los muertos, los Vedas, el Bhagavad-Gita, la Biblia o el Popol Vuh con cualquier otro libro o autor de cualquier época y lugar, aunque los enfoques y los tratamientos difieran. Si fuéramos inmortales no tendríamos necesidad de pensar en ello y ni siquiera, quizá, de crear cultura. Una obra profunda, sea de donde sea, no puede eludir los problemas 
metafísicos y uno de éstos es precisamente la muerte: "sola la vida humana corre á su fin ligera más que el viento, sin esperar renovarse si no es en la otra, que no tiene términos que la limiten", hace pensar Cervantes a Cide Hamete Benegeli (II, 53), su alter ego. Y el ingenioso Sancho le dice a su amo: "Es el caso [...] que como vuesa merced mejor sabe, todos estamos sujetos a la muerte, y que hoy somos y mañana no, y que tan presto se va el cordero como el carnero, y que nadie puede prometerse en este mundo más horas de vida de las que Dios quisiere darle; porque la muerte es sorda, y cuando llega á llamar á las puertas de nuestra vida, siempre va de priesa y no la harán detener ni ruegos, ni fuerzas, ni ceptros, ni mitras..." (II, 7). Pero don Quijote, vitalista por esencia, le responde: "Todo eso es verdad [...]; pero no sé dónde vas á parar", como tratando de evadir el tema, como diciéndole de forma contundente y hasta molesta (por su obviedad): "¡uno debe dirigirse hacia algún lado y no quedarse en un mismo sitio!" Don Quijote posee una misión en la tierra: construir una sociedad justa y equitativa, hacer que la Edad de Oro renazca en la de Hierro; no puede pensar en morir ni en la muerte, sino en destruir la injusticia reinante. Nuestro héroe se niega a morir sin antes haber obtenido la plena satisfacción, lo cual se comprueba a lo largo de la obra, no sólo en las hazañas que realiza el hidalgo, sino en la misma energía que el personaje emana, en el tono con que habla, en sus discursos y, en fin, en todo su pensamiento. Recordemos cuando proclama: "Yo soy aquel para quien están guardados los peligros, las grandes hazañas, los valerosos hechos" (I, 20), ideas de un hombre lleno de esperanza y vitalidad.

Independientemente del vínculo entre acción y pasividad, en el fondo del famoso discurso sobre las armas y las letras yace, no la dicotomía, sino la dialéctica-eminentemente vitalista- entre cuerpo y espíritu. El Caballero de la triste figura alega que quienes sostienen que las letras ocupan un puesto superior a las armas se atienen a una falacia: que los trabajos del espíritu exceden a los corporales, y que, por consiguiente, las armas sólo se ejercitan con el cuerpo, lo cual es desmentido por don Quijote. Según él, quienes profesan las armas requieren actos de fortaleza, actos que necesariamente piden 'mucho 
entendimiento’ para ejecutarlos. No se trata sólo de la fortaleza muscular, sino de astucia y pasión. Es indispensable para el guerrero el ánimo: en él se halla la totalidad cuerpo-espíritu, e incluso, a veces, el guerrero toma más del espíritu que del cuerpo. Tal actitud caballeresca y por tanto quijotesca, pretende la integración del hombre disgregado por la paulatina especialización de las áreas del conocimiento. Para comprobar lo anterior, leamos las siguientes palabras de don Quijote, referidas a la caballería andante:

Es una ciencia [...] que encierra en sí todas ó las más ciencias del mundo, á causa que el que la profesa ha de ser jurisperito, y saber las leyes de la justicia distributiva y comutativa, para dar á cada uno lo que es suyo y lo que le conviene; ha de ser teólogo, para saber dar razón de la cristiana ley que profesa, clara y distintamente, adonde quiera que le fuere pedido; ha de ser médico, y principalmente herbolario, para conocer en mitad de los despoblados y desiertos las yerbas que tienen virtud de sanar las heridas; que no ha de andar el caballero andante á cada triquete buscando quien se las cure; ha de ser astrólogo, para conocer por las estrellas cuántas horas han pasado de la noche, y en qué parte y en qué clima del mundo se halla; ha de saber las matemáticas, porque á cada paso se le ofrecerá tener necesidad dellas ... (II, 18)

Como vemos, don Quijote no pretende la separación o disgregación del conocimiento, sino la integración del espíritu por medio de la caballería. Pienso que ése, sin dudas, es uno de los mensajes del discurso sobre las armas y las letras. No obstante, alguien podrá argumentar que el caballero considera a las armas como el fin más noble, en tanto que ellas tienen por objeto la paz ("el mayor bien que los hombres pueden desear en esta vida"). Esto es cierto, pero también lo es el hecho de que don Quijote concluye que tanto las armas como las letras requieren, sin dudas, del espíritu. Diego Clemencín, en su Comentario al Quijote, advierte que la palabra 'espíritu' equivale, en el contexto del discurso que nos ocupa, a 'entendimiento o ingenio' (palabra emparentada con el francés esprit). Si entendemos 'espíritu' como el nous griego es entonces lo 'intelectual', lo que contiene la razón, un 
principio pensante, íntimo, opuesto a la materia y que trasciende lo orgánico y el tiempo. Podríamos también considerar al espíritu como la actividad de la voluntad, que da forma a las cosas con la idea. El espíritu crea para que en los objetos aparezca la idea, el mismo espíritu.

Sin embargo, es necesario aclarar a qué tipo de 'letras' se refería Cervantes en el discurso de su héroe. Dice don Quijote: "Es el fin y paradero de las letras, y no hablo ahora de las divinas, que tienen por blanco llevar y encaminar las almas al cielo; que á un fin tan sin fin como éste ninguno otro se le puede igualar; hablo de las letras humanas, que es su fin poner en su punto la justicia distributiva y dar á cada uno lo que es suyo, y entender y hacer que las buenas leyes se guarden" (I, 37). En esta cita es claro que Cervantes habla más bien de los juristas y no de los escritores o literatos en el sentido actual de estas palabras. Evidentemente, el autor complutense estima más al soldado, al combatiente, que a los magistrados o juristas. En otra parte de su magna obra, leemos: "letras sin virtud son perlas en el muladar", lo que significa que hay una escala de valores, una axiología, que debe subyacer bajo el ejercicio de la palabra escrita. Sin esos valores, las palabras se convertirían en pura forma, en un caparazón bello como una perla, pero sin contenido, vacío por adentro, como quienes escriben con una sintaxis perfecta, con una redacción y un estilo brillantes, pero que nada tienen que decir porque la intensidad vital del espíritu se ha ausentado o nunca existió. ¿Qué importan, a fin de cuentas, los minúsculos 'errores', las repeticiones innecesarias de alguna palabra o el mal uso de una coma en narraciones tan excitantes como las de Cervantes o Dostoievski? Hay algo que está más allá de la forma y que ignoran muchos estilistas a ultranza quienes evocan a Flaubert sólo por su perfección formal. La forma no es sino una trampa, un artificio para revelar los temas, las obsesiones, la vida misma, y hacer que el lector quede atrapado en esas preocupaciones vitales y las asuma casi como suyas. Eso es lo que han hecho los grandes autores, desde el anónimo del Poema de Gilgamesh, hasta la actualidad, pasando, por supuesto, por Valmiki, Vyasa, Homero, Lao Tsé, Kalidasa, Dante, Rabelais, Cervantes, Victor Hugo, Flaubert, Dostoievski... y tantos más. 
Otro elemento importante que subyace en el discurso de las armas y las letras es, por supuesto, el erasmismo, entendido no como la acción del pensamiento en la paz, sino como la obtención de paz y la crítica a todo tipo de poder y a la corrupción que emana de él. No deben olvidarse las profundas raíces erasmistas de la obra del autor complutense, cuyo maestro -López de Hoyos-era quizá más erasmista que Erasmo.

En el Elogio de la Estulticia, Erasmo de Rotterdam no hace de lado a los jurisconsultos, a quienes compara con Sísifo y a quienes representa sumergidos entre papeles, glosas y comentarios: "Los jurisconsultos -afirma la Estulticia, protagonista de este libro- pretenden el primer lugar entre los doctos y no hay quien esté tan satisfecho de sí como ellos, cuando, a la manera de nuevos Sísifos, ruedan su piedra sin descanso, acumulando leyes sobre leyes, con el mismo espíritu, aunque se refieran a cosas distintas, amontonando glosas sobre glosas y opiniones sobre opiniones y haciendo que parezca que su ciencia es la más difícil de todas, pues entienden que cuanto más trabajosa es una cosa más mérito tiene", descripción que me recuerda a algunas pinturas de Giuseppe Arcimboldo: El librero (ca. 1566), donde se representa a un hombre hecho literalmente de libros, pero sobre todo a aquellas otras, tituladas precisamente El abogado, en las que un pollo constituye el rostro de un abrigado hombre con boca de pescado y cuya barba es la cola de un pez. En su pecho lleva un sinnúmero de papeles y en su estómago varios libros. Esta imagen grotesca da una clara idea de lo absurdo que era el oficio de jurisconsulto para algunos humanistas y artistas del Renacimiento. Aquí, como ocurre con el Quijote y como ocurrirá con tantas obras satíricas, la risa oculta una lágrima.

Por último, no cabe duda que de El Quijote puede decirse -y se dirá- mucho más, no sólo en este año, en que la primera parte de dicha obra cumple 400 años, sino quizá en los próximos 400 años (o milenios), si el sistema solar, a pesar de la rapacidad y el parasitismo humanos, llega a sobrevivir para entonces. 
CITAM Derechos Reservados.

La reproducción total o parcial de este artículo se podrá hacer si el ITAM otorga la autorización previamente por escrito. 